\title{
EL FUTURO DEL ESTADO AUTONÓMICO EN ESPAÑA: ¿BLOQUEO O REFORMULACIÓN?*
}

\author{
THE FUTURE OF THE STATE OF AUTONOMIES IN SPAIN: \\ BLOCKAGE OR REFORMULATION?
}

\author{
María Jesús García MORALES ${ }^{* *}$
}

RESUMEN: El Estado autonómico fue la gran invención de la Constitución Española de 1978. España dejó de ser un Estado centralista y optó por un alto grado de descentralización. A lo largo de cuatro décadas, el Estado de las autonomías se ha consolidado, pero también debe resolver dos crisis diversas: el desgaste del modelo territorial tras cuarenta años de funcionamiento y la crisis de Cataluña. Entre los posibles escenarios, la reformulación del Estado autonómico es la salida más razonable. Es preciso identificar cuáles son los problemas de la organización territorial española y examinar de qué manera los sistemas sobre todo federales pueden ayudar a resolverlos. Sin embargo, una reforma constitucional en sentido fede-
ABSTRACT: The State of autonomies was the great invention of the Spanish Constitution of 1978. Spain ceased to be a centralist state and opted for a high degree of decentralisation. The State of Autonomies has consolidated over the past four decades, but it must also resolve two different crises: the crisis of the territorial model after 40 years in existence and the crisis in Catalonia. Among potential scenarios, the reformulation of the State of Autonomies is the most reasonable solution. It is necessary to identify the specific problems of Spanish territorial organisation and explore how other systems, especially federal ones, can help to resolve them. However, a constitutional reform in a federal sense is virtually impossible.

* Recibido el 17 de marzo de 2020; el 18 de enero de 2021.

Este trabajo se presentó en el Simposio Verfasssungsentwicklungen im Vergleich: Italien 1947-Deutschland 1949-Spanien 1978 con motivo de los aniversarios de las Constituciones de Alemania, Italia y España, los días 4 y 5 de abril de 2019, en la Academia de la Fundación Konrad Adenauer, en Berlín. El trabajo es una versión ampliada y adaptada del original publicado en alemán: María Jesús García Morales (2021). "Zukunftsperspektiven des spanischen Autonomienstaates: Blockade oder Neuformulierung?". Hermann-Josef Blanke; Siegfried Magiera; Christian Pielow y Albrecht Weber (Hrsg.), Verfasssungsentwicklungen im Vergleich: Italien 1947-Deutschland 1949-Spanien 1978. Berlin: Duncker \& Humblot.

** ORCID: 0000-0002-8436-9176. Profesora titular de Derecho constitutional en la Universitat Autònoma de Barcelona. Correo electrónico: mariajesus.garcia@uab.cat.

Boletín Mexicano de Derecho Comparado, nueva serie, año LIV, núm. 160, enero-abril de 2021, pp. 155-190. 
Esta revista forma parte del acervo de la Biblioteca Jurídica Virtual del Instituto de Investigaciones Jurídicas de la UNAM

ral es prácticamente imposible. La responsabilidad de reformar el modelo territorial corresponde a los partidos políticos y las divergencias entre ellos sobre cuáles deben ser los cambios son antagónicas. Deberían recuperarse consensos, como se hizo en España en 1978. Sin cambios, persistirán los problemas.

Palabras clave: Estado autonómico, federalismo, descentralización, secesión, asimetría.
The responsibility for reforming the territorial model rests with political parties, and the differences among them about what changes should be implemented are irremediable. Consensus needs to be reached again, as occurred in Spain in 1978. If nothing changes, problems will persist.

Keywords: State of autonomies, federalism, decentralisation, secession, asymmetry.

SumARIO: I. Introducción. II. El punto de partida: el Estado autonómico tiene el apoyo mayoritario, pero con diferencias entre territorios. Historia de un éxito y de un fracaso. III. Los problemas: El Estado autonómico debe hacer frente a dos crisis diferentes. IV. Las salidas: ¿La reformulación del Estado autonómico y el federalismo para España? V. Conclusión: El fututo del Estado autonómico es una incógnita. VI. Bibliografia.

\section{INTRODUCGIÓN}

La llamada cuestión territorial ha sido un problema constante en la historia constitucional española y también uno de los temas más conflictivos de la democracia en España desde su inicio. La Constitución Española de 1978 (en adelante CE) inventó el llamado Estado autonómico: era la gran novedad e incógnita. España se transformó rápidamente en un sistema con una descentralización territorial muy notable. Sin embargo, el tiempo ha demostrado que la cuestión territorial es un problema que la Constitución no ha podido todavía solucionar. Desde hace años, su importancia sobrepasa la organización territorial del poder, pues se ha convertido en uno de los asuntos con mayor impacto en la vida constitucional, en la política y en la convivencia en España.

A los cuarenta años de vigencia de la CE, el Estado autonómico ha pasado de ser valorado como un éxito a un fracaso. Sin embargo, los datos confirman que este modelo tiene el apoyo mayoritario, aunque no el mismo en todos los territorios. La crisis del Estado autonómico no es una, sino dos crisis distintas simultáneas y en parte sucesivas: por una

Esta obra está bajo una Licencia Creative Commons

Atribución-NoComercial-SinDerivar 4.0 Internacional, IIJ-UNAM.

Boletín Mexicano de Derecho Comparado, núm. 160, enero-abril de 2021, pp. 155-190. 
Esta revista forma parte del acervo de la Biblioteca Jurídica Virtual del Instituto de Investigaciones Jurídicas de la UNAM

parte, la crisis del modelo de organización territorial tras cuarenta años de existencia y, por otro lado, las demandas de secesión en Cataluña. Esas dos crisis necesitan soluciones diversas. Urge reformular el Estado autonómico, pero ¿cómo? El federalismo es el espejo donde observar cómo otros países resuelven problemas de división territorial de poder. Las reformas son necesarias y hay vías de solución, pero es altamente incierto que se puedan llevar a cabo.

\section{EL PUNTO DE PARTIDA: EL ESTADO AUTONÓMICO TIENE EL APOYO MAYORITARIO, PERO CON DIFERENCIAS ENTRE TERRITORIOS. HISTORIA DE UN ÉXITO Y DE UN FRACASO}

España ha sido a lo largo de su historia, mayoritariamente, un Estado sin regiones autónomas. La historia del constitucionalismo español empezó en 1812 muy influenciado por el modelo francés. Salvo el breve paréntesis de la II República, España ha sido históricamente un Estado centralizado. ${ }^{1}$ Por ello, en el ámbito comparado, es un caso interesante de cómo un modelo territorial de procedencia napoleónica se ha federalizado progresivamente (Sabine Kuhlmann y Hellmut Wollmann, 2019, p. 149). La descentralización territorial como forma de organización del poder fue en 1978 la solución para integrar en España a dos territorios con una fuerte identidad regional que reivindicaban su propia autonomía: el País Vasco y Cataluña.

El territorio de España tiene una extensión de 506,000 km2, una población de 46.5 millones de habitantes. El País Vasco tiene una superficie de 7,233 km2 y 2,170,868 de habitantes. Por su parte, Cataluña tiene una extensión que alcanza los 32,106 km2, donde viven 7,488,717 habitantes. Ambos territorios son ricos y, en particular, Cataluña, genera una de las aportaciones más importantes a la economía española. ${ }^{2}$ Cata-

1 Eliseo Aja (2014, pp. 31-36). Durante la I República se redactó el Proyecto de Constitución Federal de 1873 que no llegó a ser aprobado por las Cortes. Por ello, la Constitución de la II República es el primer texto donde se aprobó la descentralización política en España. (Alejandro Nieto García, 2016, pp. 1069-1088; Joaquín Varela Suanzes-Carpegna, 2016, pp. 1089-1109).

2 Contabilidad Regional de España. Revisión estadística 2019. INE: En 2018, Cataluña tuvo una aportación al PIB del19\%, sólo superada por la Comunidad de Madrid con el 19.2\%, https//wrwre.ine.es. 
Esta revista forma parte del acervo de la Biblioteca Jurídica Virtual del Instituto de Investigaciones Jurídicas de la UNAM

luña y el País Vasco tienen una historia, una cultura y una lengua propias. ${ }^{3}$ Los dos territorios han reivindicado el reconocimiento de una posición singular en el conjunto del Estado.

$\mathrm{El}$ artículo 2 de la CE, uno de los que generaron más debate durante la elaboración de la Constitución, refleja la indeterminación del modelo de organización territorial en España: "La Constitución se fundamenta en la indisoluble unidad de la Nación española [...], y reconoce y garantiza el derecho a la autonomía de las nacionalidades y regiones que la integran [...]". Con esta ambigua fórmula, fruto de posiciones políticas antagónicas, el nacionalismo moderado se sintió en aquel momento integrado en la Constitución (Jordi Solé Tura, 2019, p. 135).

El título VIII de la CE (De la organización territorial del Estado) concretó el artículo 2 de la CE: "España se organizaría en comunidades autónomas, además, de municipios y provincias" (artículo 137 de la CE). De esta manera, junto al Estado central, la distribución vertical del poder se diseñó en tres niveles territoriales: las comunidades autónomas con una autonomía política - con capacidad de autogobierno y autoorganización, cuya máxima expresión y rasgo definitorio frente a la autonomía administrativa es la capacidad de aprobar leyes en su ámbito de competenciasy los municipios y provincias con autonomía administrativa, que integran la administración local. ${ }^{4}$

A diferencia de las provincias que tienen una larga tradición en la historia constitucional española, pues su origen se remonta a la Constitución de Cádiz de 1812, que siguió el modelo del departamento francés y su esquema de administración centralista siguiendo criterios de eficacia y no identitarios,${ }^{5}$ las autonomías como tales no han existido hasta la Constitución de 1978. Las comunidades autónomas se constituyeron como nuevas

3 Más del 20\% de la población habla vasco, una lengua de origen no latino: $22.3 \%$ en 1991 y 28.4\% en 2016, VI Encuesta Sociolingüística (2016), http://wrereeuskadi.eus. En Cataluña, el catalán, una lengua latina, $94.4 \%$ de la población lo entiende y $81.2 \%$ lo habla, en 1981 sólo era 31.5\%, Enquesta d'usos lingüístics de la població (2018), https:// wrere.idescat.cat.

4 Desde su más temprana jurisprudencia, véase SSTC 32/1981, 76/1983.

5 Las provincias españolas se previeron en la Constitución de Cádiz, pero datan de 1833 con el Decreto de división provincial de Javier de Burgos (Francisco Velasco Caballero, 2011, p. 627; Beatriz Tomás Mallén, 2018, p. 1949). Sobre el enraizamiento de la provincia en la vida española, el clásico de José Ortega y Gasset (1967, p. 52, p. 161).

Esta obra está bajo una Licencia Creative Commons

Atribución-NoComercial-SinDerivar 4.0 Internacional, IIJ-UNAM.

Boletín Mexicano de Derecho Comparado, núm. 160, enero-abril de 2021, pp. 155-190. 
Esta revista forma parte del acervo de la Biblioteca Jurídica Virtual del Instituto de Investigaciones Jurídicas de la UNAM

entidades políticas sobre la base de "las provincias limítrofes con características históricas, culturales y económicas comunes, los territorios insulares y las provincias con entidad regional histórica" (CE, art. 143; Eliseo Aja et al., 1985, pp. 91-96).

En ningún momento, la Constitución define a España como un Estado autonómico, ni menos aun como un Estado federal. A diferencia de varias Constituciones del entorno europeo como los textos alemán, austriaco o suizo - donde se mencionan cada una de las unidades territoriales: Länder o, en su caso, cantones— ${ }^{6}{ }^{6}$ en el texto español ni dice cuáles son, ni tampoco se enumeran las comunidades autónomas que componen el Estado autonómico. La Constitución permite un sistema descentralizado, pero no lo desarrolla (Pedro Cruz Villalón, 1981, pp. 53-63).

No existe deliberadamente en la CE un modelo territorial. Se trata de un modelo abierto que debía ir concretándose en el tiempo (Luis López Guerra, 1995, p. 189; Manuel Aragón Reyes, 2006, pp. 1-24). La Constitución desplazaba esa responsabilidad a los actores políticos. Con ese diseño, en 1978, hubiera sido posible una autonomía política sólo para el País Vasco, Cataluña y Galicia, las llamadas "comunidades históricas", ${ }^{7}$ y una descentralización administrativa para el resto.

$\mathrm{Al}$ buscar una fórmula para integrar en España a nacionalistas vascos y catalanes, el territorio se acabó dividiendo en diecisiete comunidades autónomas, ${ }^{8}$ cada una de las cuales tiene un Parlamento, un gobierno y sus propias instituciones de autogobierno, salvo el Poder Judicial que es único y corresponde al Estado central. Hay también dos ciudades autónomas en el Norte de África (Ceuta y Melilla) con gobierno propio, pero sin Parlamento.

6 La Ley Fundamental de Bonn menciona los dieciséis länder en el preámbulo, la Constitución austriaca los ocho Länder (artículo 2) y la Constitución suiza los veintiséis cantones (artículo 1).

7 Esta denominación no está en la Constitución. Se utiliza para hacer referencia a los tres territorios que, bajo la II República, "en el pasado hubieren plebiscitado favorablemente proyectos de Estatuto de autonomía" (reconocimiento indirecto en la disposición transitoria segunda de la CE). A diferencia del País Vasco y de Cataluña, la identidad regional y el sentimiento nacionalista no es tan acusado en Galicia.

8 Por orden de constitución como comunidad autónoma: País Vasco, Cataluña, Galicia, Andalucía, Principado de Asturias, Cantabria, La Rioja, Región de Murcia, Comunidad Valenciana, Aragón, Castilla-La Mancha, Canarias, Comunidad Foral de Navarra, Extremadura, Islas Baleares, Comunidad de Madrid y Castilla y León. 
Esta revista forma parte del acervo de la Biblioteca Jurídica Virtual del Instituto de Investigaciones Jurídicas de la UNAM

En la actualidad, la autonomía no es algo que corresponda sólo al País Vasco y a Cataluña, sino a diecisiete comunidades autónomas. La posibilidad de un Estado asimétrico, con un estatus especial para el País Vasco y Cataluña, acabó en una España simétrica, con una sustancial igualdad entre todas las comunidades autónomas, salvo excepciones, como claramente el sistema de financiación propio del País Vasco. Los grandes partidos de ámbito estatal decidieron ese desarrollo mediante pactos políticos, los llamados "Pactos Autonómicos". 9

La percepción sobre el Estado autonómico por parte de los ciudadanos y los partidos políticos es diferente. Las encuestas muestran que el apoyo de los ciudadanos al Estado autonómico ha ido subiendo paulatinamente hasta situarse por encima de 65\% (en 2019). ${ }^{10}$ Tanto el número de personas que prefieren un Estado sin comunidades autónomas (15.9\%), ${ }^{11}$ como de los que están en favor de la posibilidad de independencia de las comunidades autónomas ha ido bajando y representa una minoría $(7.9 \%) .{ }^{12}$

Esos datos deben matizarse según los territorios. En el País Vasco y Cataluña las demandas de secesión son ciertamente más altas que en el resto de España. Sin embargo, en ambos casos la mayoría de la población se muestra en favor de la unidad de España. El independentismo es la opción preferida para una cuarta parte de los vascos $(22 \%)$, mientras que esa opción en Cataluña se acerca a la mitad de la población $(43.7 \%) .{ }^{13}$

La valoración del Estado autonómico por parte de los partidos políticos es curiosamente muchas veces más negativa que la que tienen los ciudadanos. Los dos grandes partidos, la socialdemocracia (PSOE) y los conservadores (PP), así como otros partidos de ámbito estatal, como

9 Por medio de los I Acuerdos Autonómicos de 1981 (UCD-PSOE) se cerró el mapa de comunidades autónomas y mediante los II Pactos Autonómicos de 1992 (PSOE-PP) se pactó la igualación de competencias entre comunidades autónomas.

10 La mayoría de los españoles y las españolas se muestran favorables a mantener el Estado autonómico, tal y como está, 43.3\% en junio de 2019 (frente al 32.6\% en julio de 2013). Un porcentaje más bajo representan tanto aquellos que creen que las comunidades autónomas deben tener menor o mayor autonomía (alrededor de 13\% y 12\% respectivamente). Barómetros CIS, http://wrewe.cis.es.

11 Barómetros CIS: 15.9\% (junio 2019) frente 9.7\% (julio 2019), http://wrew.cis.es.

12 Barómetros CIS: 7.9\% (junio 2019) frente 12.4\% (noviembre 2014), http://wrere.cis.es.

13 País Vasco: Euskobarómetro (2019, 42), https://wrwre.ehu.eu. Cataluña: CEO Dossier de premsa del BOP. 3a onada $(2019,63)$. El punto máximo fue 48.7\% en octubre de 2017 , http://wrere.ceo.gencat.cat.

Esta obra está bajo una Licencia Creative Commons

Atribución-NoComercial-SinDerivar 4.0 Internacional, IIJ-UNAM.

Boletin Mexicano de Derecho Comparado, núm. 160, enero-abril de 2021, pp. 155-190. 
Esta revista forma parte del acervo de la Biblioteca Jurídica Virtual del Instituto de Investigaciones Jurídicas de la UNAM

los liberales (Ciudadanos) y aquellos que se sitúan en el espectro de la izquierda (Podemos), apoyan el Estado autonómico. Sin embargo, disienten sobre cómo la organización territorial debe evolucionar en España. Sólo el partido de ultraderecha defiende una supresión de las comunidades autónomas. Los partidos nacionalistas y separatistas en el País Vasco y Cataluña mantienen un discurso que critica habitualmente el Estado autonómico.

Los partidos nacionalistas y separatistas son clave para entender la vida constitucional y la cuestión territorial en España. Ello radica no sólo en que han gobernado casi ininterrumpidamente en estas comunidades autónomas, sino también en su decisiva influencia en el Parlamento y en el gobierno central. El sistema español es parlamentario en el nivel central y autonómico: ergo un presidente de gobierno sale elegido por un parlamento y es responsable ante éste.

En el nivel central, cuando ninguno de los dos grandes partidos estatales tiene mayoría absoluta, deben gobernar en minoría habitualmente con el apoyo de los partidos nacionalistas y separatistas periféricos en el Parlamento central. ${ }^{14}$ Se trata de una dinámica frecuente en un país donde no ha habido tradición de gobiernos de coalición en el Estado central. ${ }^{15}$ Los partidos nacionalistas y separatistas no pueden prohibirse, aunque persigan fines contrarios a la Constitución, como puede ser la ruptura de la integridad territorial, pues el Tribunal Constitucional español - a diferencia del Tribunal Constitucional Federal alemán - ha rechazado el principio de la democracia militante (SSTC 48/2003, 235/2007, $12 / 2008)$.

Más allá de la percepción por los ciudadanos y por los partidos políticos, la historia del Estado autonómico se mide por hechos objetivos. Aunque todavía existe una brecha entre comunidades autónomas ricas y pobres, ${ }^{16}$ se han reducido las enormes desigualdades económicas en-

14 En la vida política española, el papel de los partidos nacionalistas y separatistas se visibiliza especialmente en dos momentos claves: la elección de presidente del gobierno en España mediante la votación de la investidura y el debate y la aprobación parlamentarios de la Ley General de Presupuestos del Estado.

15 La primera coalición de un Gobierno de España (PSOE-Podemos) desde la II República se presentó el 30 de diciembre de 2019.

16 Las comunidades con PIB per capita más alta son por este orden: Comunidad de Madrid, el País Vasco, Navarra y Cataluña (INE, 2019, p. 29).

Esta obra está bajo una Licencia Creative Commons 
Esta revista forma parte del acervo de la Biblioteca Jurídica Virtual del Instituto de Investigaciones Jurídicas de la UNAM

tre territorios de las que se partían en 1978. El Estado social se implantó en España con el Estado autonómico, porque la mayoría de los ámbitos de la política social (asistencia y servicios sociales, sanidad o educación) caen en el ámbito de competencia de las comunidades autónomas. Por lo que respecta al País Vasco y Cataluña, ambos territorios han tenido, con la Constitución de 1978, el nivel más alto de autonomía de toda su historia.

La aceptación del Estado autonómico empezó, sin embargo, a resquebrajarse a partir de 2008. La crisis económica no llegó sola. Las comunidades autónomas ejecutaron los recortes en prestaciones sociales y se cuestionó el exceso de gasto en las comunidades autónomas: la descentralización territorial era cara, ineficiente y, para los partidos nacionalistas y separatistas, además, insuficiente. En paralelo a la crisis económica, en el País Vasco y Cataluña crecieron las demandas de más autonomía. Mientras en el País Vasco, esas tendencias se frenaron, en Cataluña crecieron y han llegado hasta cuotas nunca vistas. Es el indicador más claro de que el Estado autonómico no ha podido integrar a ciertos territorios el objetivo con el que se inventó - en un proyecto común llamado España (véase José Tudela, 2016, pp. 185-207).

\section{LOS PROBLEMAS: EL ESTADO AUTONÓMICO DEBE HACER FRENTE A DOS CRISIS DIFERENTES}

El Estado autonómico debe encarar dos crisis diferentes: por un lado, la crisis del sistema de organización territorial español tras cuarenta años de existencia y, por otro, la crisis de Cataluña. El intento de secesión unilateral en el marco de la crisis catalana no es la causa, sino la consecuencia de una crisis previa del Estado autonómico en su conjunto.

\section{El desgaste del sistema de organización territorial en España tras cuarenta años de existencia}

El conflicto con Cataluña no puede entenderse sin tener en cuenta los problemas estructurales y funcionales que el Estado autonómico viene arrastrando desde hace años (Santiago Muñoz Machado, 2013, pp. 1056). Estos problemas radican esencialmente en materia de financiación, 
Esta revista forma parte del acervo de la Biblioteca Jurídica Virtual del Instituto de Investigaciones Jurídicas de la UNAM

distribución de competencias, así como relaciones entre el Estado central y las comunidades autónomas y entre las propias comunidades autónomas.

La CE no regula una "Constitución financiera", por lo menos en el sentido de la Ley Fundamental de Bonn. Por ello, en España no se habla de Constitución financiera, sino de sistema de financiación. Una de las peculiaridades más significativas del Estado autonómico es que hay dos sistemas de financiación: uno, para el País Vasco y también Navarra, que se halla garantizado en la disposición adicional primera de la $\mathrm{CE}$, y, otro, para el resto de las comunidades autónomas.

El sistema de financiación que rige en el País Vasco y Navarra constituye un privilegio histórico, que permite una gran autonomía financiera a ambos territorios y una menor aportación a la solidaridad interterritorial que el resto de las comunidades autónomas. Cataluña es una de las comunidades que más aporta en comparación con los ingresos que recibe. ${ }^{17}$ Ese desequilibrio ha sido un factor clave para el incremento exponencial de los partidarios de la independencia.

Otro tema no exento de problemas en cada país suele ser el sistema de reparto de competencias. Por su parte, la distribución de competencias en España se basa en muchos ámbitos en una técnica de reparto donde las bases o la legislación básica son unos principios generales que corresponden regular al Estado central, mientras que el desarrollo legislativo y ejecutivo de los mismos corresponde al Parlamento, o, en su caso, al gobierno de las comunidades autónomas (por ejemplo, "bases y coordinación de la planificación general de la actividad económica", conforme al artículo 149.1. 13 ${ }^{\mathrm{a}}$ de la CE). Esta técnica de reparto competencial ha provocado que el Estado central haya podido intervenir en casi todas las competencias de las comunidades autónomas.

Esta circunstancia ha generado muchos conflictos, especialmente con el País Vasco y con Cataluña, dos territorios especialmente reivindicativos de sus competencias (y de más competencias). Hasta la crisis catalana, tales conflictos se han presentado en términos jurídicos ante el Tri-

17 Según datos publicados en 2019: Cataluña se encuentra en la tercera posición respecto a las comunidades autónomas que más recursos aportan por habitante tras la Comunidad de Madrid e Islas Baleares y en la décima posición en relación con los ingresos. Ministerio de Hacienda (2017). Informe sobre financiación definitiva de las comunidades autónomas por medio del sistema de financiación, http://hacienda.gob.es. Sobre los sistemas de financiación en España, véase Antoni Zabalza y Julio López-Laborda (2017, pp. 119-152). 
Esta revista forma parte del acervo de la Biblioteca Jurídica Virtual del Instituto de Investigaciones Jurídicas de la UNAM

bunal Constitucional. Esta tarea de delimitación de competencias entre el Estado central y las comunidades autónomas ha sido una de las más importantes que ha llevado a cabo la jurisdicción constitucional española (Pedro Cruz Villalón, 1991, pp. 249-260). Las soluciones del Tribunal Constitucional tienen naturaleza jurídica y, consiguientemente, son insatisfactorias siempre políticamente para una de las partes.

La cuestión de las relaciones entre el Estado central y las comunidades autónomas y entre comunidades autónomas es también otro importante problema en España. No hay una institución donde el Estado central y las comunidades autónomas puedan cooperar en la elaboración de las leyes del Estado central que afectan a las competencias autonómicas. El Senado no es una Cámara de representación territorial, una cuestión pendiente en casi todos los sistemas federales y sin soluciones claras (véase José María Porras Ramírez, 2021, pp. 322-334). Al no existir una institución política donde discutir estos temas, los conflictos entre el Estado central y las comunidades autónomas son recurrentes.

La cooperación intergubernamental es un problema que presenta perfiles propios en el Estado autonómico (María Jesús García Morales, 2016, pp. 121-146). A diferencia de los países descentralizados o federales de su entorno, en España no existe casi cooperación formalizada entre las comunidades autónomas (cooperación horizontal). No hay una Conferencia de Presidentes de las Comunidades Autónomas, ni Conferencias Sectoriales donde sólo se reúnen las comunidades. Los acuerdos de cooperación o convenios interadministrativos interautonómicos son casi inexistentes. ${ }^{18}$ No hay autocoordinación entre comunidades autónomas.

La cooperación existente se formaliza entre el Estado central y las comunidades autónomas (cooperación vertical). En 2004, se constituyó la Conferencia de Presidentes formada por el presidente del gobierno central y los jefes de los ejecutivos de cada una de las comunidades autónomas. Sin embargo, esta Conferencia no se ha reunido regularmente. Resulta sorprendente que los actores políticos no hayan percibido como necesaria una institución que debería ser el símbolo máximo del diálogo interterritorial.

18 Los convenios entre comunidades autónomas son la única técnica de cooperación regulada por la CE, art. 145. Al respecto, véase Ignacio González García (201 1, pp. 303412) y Vicente Juan Calafell (2006, pp. 154-192).

Esta obra está bajo una Licencia Creative Commons

Atribución-NoComercial-SinDerivar 4.0 Internacional, IIJ-UNAM.

Boletín Mexicano de Derecho Comparado, núm. 160, enero-abril de 2021, pp. 155-190. 
Esta revista forma parte del acervo de la Biblioteca Jurídica Virtual del Instituto de Investigaciones Jurídicas de la UNAM

El instrumento de cooperación más importante en España son las Conferencias Sectoriales multilaterales, entre las más relevantes, se cuentan las Conferencias Sectoriales de Agricultura, de Medio Ambiente o de Sanidad. También una cuestión tan crucial como la participación de las comunidades autónomas en asuntos europeos — un tema que no está regulado en la Constitución - se realiza por medio de las correspondientes Conferencias Sectoriales. ${ }^{19}$ Son miembros de las Conferencias Sectoriales los ministros del gobierno central y los consejos autonómicos del ramo. La presidencia de una conferencia sectorial corresponde siempre al ministro del gobierno central. Las comunidades autónomas no perciben a estas conferencias como un instrumento de participación en asuntos generales, sino más bien como instituciones del gobierno central. En las conferencias sectoriales, son frecuentes las ausencias de representantes del País Vasco y Cataluña.

Los gobiernos nacionalistas o separatistas prefieren claramente el procedimiento bilateral en lugar de la cooperación multilateral. La cooperación bilateral formalizada por medio de las llamadas comisiones bilaterales entre miembros del gobierno central y del Ejecutivo de una comunidad autónoma es una singularidad del Estado autonómico. Existen comisiones bilaterales entre el Estado central y cada una de las comunidades autónomas. Sin embargo, la bilateralidad tiene un fuerte simbolismo en el imaginario nacionalista: representa un dualismo (por ejemplo, catalán vs. español), donde se reúnen dos gobiernos sin las otras comunidades autónomas, y proporciona la percepción del reconocimiento de la posición especial de ese territorio respecto al resto. En la praxis, es dificil encontrar temas que sólo pueden tratarse con una comunidad autónoma (María Jesús García Morales, 2013, pp. 92-96).

19 La entrada de España en las Comunidades Europeas (hoy Unión Europea) se produce el 1o. de enero de 1986, por tanto, con posterioridad a la aprobación de la Constitución. A diferencia de Ley Fundamental de Bonn o la Constitución italiana, la participación de los entes territoriales en asuntos europeos no está regulada en el texto constitucional, sino por medio de acuerdos de una conferencia sectorial, la Conferencia de Asuntos Relacionados con la Unión Europea, donde se fija como locus institucional de dicha participación las Conferencias Sectoriales, mientras que en Alemania el texto constitucional prevé que sea el Bundesrat o en Italia se deja la cuestión abierta con remisión a la decisión del legislador. Sobre la necesidad de atención constitucional a esta cuestión (Ana M. Carmona Contreras, 2019, pp. 86-89). 
Esta revista forma parte del acervo de la Biblioteca Jurídica Virtual del Instituto de Investigaciones Jurídicas de la UNAM

¿Y la administración local? Hasta el momento, el foco de los desafíos de la organización territorial española se ha planteado en las relaciones entre el Estado y las comunidades autónomas, sin contemplar la administración local que, en ese debate ha sido relegada a la irrelevancia política. Como se vio, la Constitución reconoce, junto a las comunidades autónomas, dos niveles más de división territorial del poder: la provincia y los municipios (CE, art. 137).

Las provincias - con casi dos siglos de existencia e inspiradas en el centralismo francés - son una pieza de difícil encaje en la nueva organización territorial de 1978. Deben coexistir con las comunidades autonómicas que responden a una filosofia diversa de la eficacia administrativa y tienen una autonomía cualitativamente distinta: la autonomía política. La decisión constitucional de mantener la provincia tiene consecuencias: preserva su garantía institucional y la hace indisponible para el legislador (Eduardo García de Enterría, 1991, pp. 7-10; Mayte Salvador Crespo, 2007). La función más importante de las provincias es prestar asistencia financiera y técnica a los municipios más pequeños, pero las comunidades autónomas pueden crear entes locales supramunicipales, de modo que su superposición con la provincia es disfuncional en términos de eficacia y no concita respaldo en algunos territorios, como particularmente Cataluña y el País Vasco (Luis Cosculluela Montaner, 2011, pp. 45-67).

\section{La crisis de Cataluña}

Desde 2010, a los problemas de la organización territorial española se ha sumado un nuevo reto, el más importante al que el Estado de las Autonomías debe hacer frente: la crisis de Cataluña y las demandas de secesión. La crisis catalana es la cara más visible de las crecientes tendencias secesionistas en países de la Unión Europea ${ }^{20}$ y la secesión un viejo conocido en el federalismo comparado. ${ }^{21}$

El gobierno central optó por trasladar el problema a los tribunales que han dado una respuesta jurídica ya sea en sede nacional, o bien euro-

20 Así, el Tribunal Constitucional Federal sobre el caso de Baviera (2 BvR 349/16) y la Corte Costituzionale italiana (sentencia 118/2015) sobre las leyes regionales del Véneto.

21 Texas vs. White, de 1868, del Tribunal Supremo de los Estados Unidos de América, Reference Re Secession of Quebec del Tribunal Supremo de Canadá, del 20 de agosto de 1998.

Esta obra está bajo una Licencia Creative Commons

Atribución-NoComercial-SinDerivar 4.0 Internacional, IIJ-UNAM.

Boletín Mexicano de Derecho Comparado, núm. 160, enero-abril de 2021, pp. 155-190. 
Esta revista forma parte del acervo de la Biblioteca Jurídica Virtual del Instituto de Investigaciones Jurídicas de la UNAM

pea, que no puede por sí sola resolver una crisis de naturaleza política. ${ }^{22}$ Por otro lado, los nacionalistas (posteriormente, separatistas), que se habían centrado en construir la idea de "nación catalana" distinta de la española, pero dentro de España, han iniciado una nueva fase basada en la desobediencia al Estado de derecho y a la Constitución - que no consideran suyos - , así como en la demanda de independencia unilateral al margen del rule of law (Gonzalo Quintero Olivares, 2019b, p. 68).

Las señales de alarma empezaron hace una década: el número de partidarios de la independencia crecía enormemente. En 2007, 14.5\% era partidario de la independencia. ${ }^{23}$ Diez años más tarde ese porcentaje superaba $40 \%$. El ascenso del movimiento separatista tiene varias causas, pero hay una fecha clave. ${ }^{24}$ En 2010, el Tribunal Constitucional declaró determinadas previsiones del Estatuto de Autonomía catalán inconstitucionales. Estas disposiciones regulaban aspectos muy sensibles y con gran relevancia para Cataluña, entre ellos, la autodefinición de Cataluña como nación en el Preámbulo, la lengua catalana como lengua preferente en la escuela, en la administración pública y en los medios de comunicación catalanes, así como la regulación de un sistema de financiación para Cataluña similar al del País Vasco (STC 31/2010).

El nuevo Estatuto de Autonomía catalán pretendía dar a Cataluña una posición especial en el marco del Estado autonómico, pero sin una previa reforma constitucional. La sentencia del Tribunal Constitucional provocó una profunda frustración en una parte muy significativa de la población catalana. A continuación de ese pronunciamiento, el partido nacionalista conservador catalán solicitó al Estado central la regulación de un sistema de financiación para Cataluña, el llamado "pacto fiscal", similar al que había previsto el Estatuto. Sin embargo, esa reivindicación no fue atendida por el gobierno de Madrid, que alegó que dicha reforma sólo podía hacerse previa revisión de la Constitución. A partir de ese momento, el nacionalismo conservador catalán que ha gobernado Cataluña durante más de veinte años y que había apoyado parlamentariamente

22 Por ejemplo, STS 459/2019 del 14 de octubre de 2019 (proceso penal contra los líderes independentistas), Sentencia del Tribunal de Justicia de la Unión Europea (Gran Sala), del 19 de diciembre de 2019 (asunto C-502/19 Junqueras i Vies).

23 Sondeig Opinió Catalunya (2019), ICPS, https://wrerw.icps.cat.

24 Un relevante testimonio a cargo de quien fue Letrado Mayor del Parlamento de Cataluña, Antoni Bayona (2019, pp. 105-131).

Esta obra está bajo una Licencia Creative Commons Atribución-NoComercial-SinDerivar 4.0 Internacional, IIJ-UNAM. Boletín Mexicano de Derecho Comparado, núm. 160, enero-abril de 2021, pp. 155-190. 
Esta revista forma parte del acervo de la Biblioteca Jurídica Virtual del Instituto de Investigaciones Jurídicas de la UNAM

a los (diversos) gobiernos de España en minoría - ya fueran del PSOE, ya fueran del PP-, inició su viraje hace las demandas de independencia.

En la CE no está previsto el derecho a la autodeterminación. El referéndum suele ser una de las vías para plantear la secesión de una parte del territorio. El texto constitucional prevé en contadas ocasiones la celebración de esta forma de democracia directa.

El referéndum consultivo se prevé para decisiones políticas de especial trascendencia. La decisión formal de convocatoria corresponde al rey, pero la propuesta y decisión material es del presidente del gobierno, previamente autorizado por el Congreso de los Diputados (CE, art. 92). Las comunidades autónomas pueden convocar consultas populares no referendarias, pero no referéndums sin la autorización del Estado central (CE, art. 149.1.32). La regulación española en esta materia es más restrictiva que en otros ordenamientos jurídicos. Ello se debe a los intentos de los partidos nacionalistas y separatistas en España por materializar referéndums de autodeterminación (Carlos Garrido y Eva Saénz, 2019, p. 15. En el panorama comparado, Karl-Peter Sommermann, 2015, p. 11).

El Tribunal Constitucional no ha cerrado la puerta a un referéndum consultivo de autodeterminación, pero en la práctica los requisitos exigidos lo hacen extraordinariamente difícil. En España, la jurisprudencia constitucional considera que un referéndum consultivo sobre la independencia es posible bajo dos condiciones. ${ }^{25}$

Primero, preguntar a la población de un territorio sobre la independencia no es una consulta popular no referendaria, sino un referéndum. Las consultas se ciñen expresamente al ámbito de las competencias autonómicas y, en su caso, locales. La pregunta sobre una eventual secesión de una parte del territorio excedería las competencias de una comunidad autónoma. Una parte del territorio no puede decidir sobre la integridad territorial del Estado, sino que dicha cuestión corresponde a España en su conjunto.

Y, segundo, un referéndum de independencia sólo es legítimo previa reforma de la Constitución. El texto constitucional prevé la unidad y la indivisibilidad del territorio español (CE, art. 2) y una eventual respuesta afirmativa a semejante pregunta sería una reforma de la Constitución

25 SSTG 103/2008, 51/2017, 114/2017. STG 114/2017 recurre expresamente a Reference Re Secession of Quebec del Tribunal Supremo de Canadá, del 20 de agosto de 1998.

Esta obra está bajo una Licencia Creative Commons

Atribución-NoComercial-SinDerivar 4.0 Internacional, IIJ-UNAM.

Boletín Mexicano de Derecho Comparado, núm. 160, enero-abril de 2021, pp. 155-190. 
Esta revista forma parte del acervo de la Biblioteca Jurídica Virtual del Instituto de Investigaciones Jurídicas de la UNAM

por un procedimiento no previsto para ello. No pueden ser, por tanto, objeto de pregunta cuestiones fundamentales que quedaron cerradas por el constituyente y que quedan sustraídas de los poderes constituidos, sin antes una reforma constitucional.

De este modo, la Constitución permite que un partido político pueda defender la independencia de un territorio, pero no permite que, cuando ese partido llegue al poder, el Parlamento y el gobierno de una comunidad autónoma organicen un referéndum de autodeterminación sin las condiciones que ha señalado la mencionada jurisprudencia.

A pesar de las reiteradas prohibiciones del Tribunal Constitucional, ${ }^{26}$ el 1o. de octubre de 2017, se convocó en Cataluña un referéndum ilegal y pocos días después se declaró en el Parlamento autonómico la independencia de este territorio (Carmen Plaza, 2018, pp. 373-392; Eduard Roig, 2017, pp. 24-61; Josu de Miguel, 2018, pp. 133-166).

La primera aplicación del artículo 155 de la $\mathrm{CE}$ - una importación casi textual de la coerción federal prevista en el artículo 37 de la Ley Fundamental de Bonn - fue la respuesta del Estado central a la reiterada desobediencia del gobierno y del Parlamento catalanes. La primera aplicación del artículo 155 de la CE se concretó en la adopción de medidas duras, tales como el cese del presidente y del gobierno de Cataluña, así como la disolución del Parlamento catalán. ${ }^{27}$

La aplicación del artículo 155 de la CE frenó un proceso de secesión. Las medidas adoptadas han servido para restablecer el cumplimiento de la Constitución en una parte del territorio, pero no han resuelto la crisis catalana. La praxis ha demostrado que el artículo 155 de la CE no es un instrumento útil, ni suficiente, cuando la crisis constitucional que ha

26 De forma particularmente explícita: Providencia del 7 de septiembre de 2017, que incluyó advertencias directas y expresas y fue notificada a todos los miembros del Gobierno catalán. Además, Providencia del 4 de abril de 2017, SSTC 90/2017, 51/2017, ATC 24/2017, ATC 141/2016, Providencia del 1o. de agosto de 2016, SSTC 259/2015, 135/2015, 137/2015, 138/2015, 317/2015, 103/2008. Nótese el abultado número de resoluciones que han tratado la crisis catalana. Y es que una de las peculiaridades del caso español es el gran número de resoluciones que han ocupado al Tribunal Constitucional con el tema de la secesión. Específicamente sobre la desobediencia al Tribunal Constitucional (Gonzalo Quintero, 2019a, p. 123).

27 En vigor desde el 27 de octubre de 2017 hasta el 2 de junio de 2018. Medidas declaradas constitucionales (SSTC 89/2019, 90/2019). Véase Javier García Roca (2019, pp. 503-524). 
Esta revista forma parte del acervo de la Biblioteca Jurídica Virtual del Instituto de Investigaciones Jurídicas de la UNAM

desencadenado su aplicación se debe a un problema político, como es un intento de secesión apoyado por una parte muy importante de la población (María Jesús García Morales, 2019, pp. 12 y 13).

Tras la aplicación del artículo 155 de la CE, los partidos separatistas han ganado de nuevo las elecciones en Cataluña. Hay un gobierno y un Parlamento, que insisten en actuar en contra del orden constitucional. Más de dos millones de personas - sobre cinco millones de electoresno creen en el ordenamiento constitucional, aprueban la desobediencia al mismo y no quieren ser más españoles.

Es importante destacar que los separatistas no han alcanzado (de momento) el 50\% de los votos, un techo de cristal que no se ha roto (todavía) y que, en caso de conseguirse, tendría un importante valor simbólico y político. En las últimas elecciones autonómicas consiguieron $47.3 \%$ de los votos frente $51.7 \%$ que suman las opciones que, de una y otra forma, no reivindican la independencia. (Elecciones autonómicas del 21 de diciembre de 2017, Francesc Pallarés, 2018, p. 437)

Sin embargo, los separatistas tienen la mayoría en el Parlamento catalán, algo que viene sucediendo a causa del vigente sistema electoral y de cómo traduce los votos en escaños. Cataluña no constituye a efectos electorales una única demarcación. El derecho electoral prevé cuatro demarcaciones electorales en este territorio (las cuatro provincias catalanas), en las que los territorios más rurales y menos poblados están sobrerrepresentados. ${ }^{28}$ Los separatistas no tienen en las elecciones autonómicas una mayoría de votos, ni la han tenido antes. Pero, desde 2010, el número de personas que en Cataluña no se sienten españoles es muy considerable, lo que constituye obviamente un motivo de enorme preocupación y reflexión.

28 En Cataluña las cuatro provincias (y circunscripciones electorales) son Barcelona, Tarragona, Girona y Lleida, siendo estas dos últimas las que cuentan con menos habitantes y donde más votos obtienen las opciones separatistas, véase por ejemplo, los resultados electorales en 2017 (Francesc Pallarés, 2018, p. 436). Sobre la proporcionalidad de un sistema electoral en zonas escasamente pobladas en el ámbito del Convenio Europeo de Derechos Humanos (Jochen Frowein y Wolfgang Peukert, 2009, pp. 684-685). Sobre el debate proporcionalidad, igualdad y tamaño de las circunscripciones, el trabajo clásico de Jochen Frowein (1974, pp. 72-110). Sobre el caso español, Dieter Nohlen y Rainer Olaf Schultze (1985, p. 183; Dieter Nohlen, 2019, p. 16). 
Esta revista forma parte del acervo de la Biblioteca Jurídica Virtual del Instituto de Investigaciones Jurídicas de la UNAM

\section{LAS SALIDAS: ¿LA REFORMULACIÓN DEL ESTADO AUTONÓMICO Y EL FEDERALISMO PARA ESPAÑA?}

En este contexto, ¿cuáles son los posibles escenarios y salidas? La disolución del Estado autonómico parece impensable: a pesar de sus problemas, esta organización territorial tiene el apoyo mayoritario de la población, aunque en unos territorios, más que en otros, y, además, las demandas de secesión no tienen (por el momento) el respaldo de la mayoría, ni en Cataluña, ni en el País Vasco. El escenario actual de mantener el Estado autonómico sin reformas prolongará la situación de bloqueo.

Por ello, la solución más viable para salir del atasco y del impasse pasa por la reformulación de la organización territorial española. Lo ideal y lo más razonable sería una gran reforma del Estado autonómico que, identificados cuáles son nuestros problemas, examine cómo han solucionado esos mismos problemas otros países federales o con un nivel de descentralización similar. Ello debería mejorar el sistema existente y conseguir dar un acomodo al separatismo que permitiera seguir juntos y dar más estabilidad a la vida constitucional española.

\section{Algo sobre el federalismo en España}

En España no existe tradición federal. En la historia constitucional española ha dominado la voluntad de construir el Estado sobre el modelo centralista y monolingüe. El federalismo en España ha tenido más detractores que defensores. Para sus detractores, la diversidad y el federalismo se han visto históricamente como potencial riesgo de disgregación, mientras que para sus defensores era justamente la vía que la evitaba (Xavier Arbós, 2006, p. 16).

El pensamiento federal, además, ha surgido, habitualmente, vinculado a una ideología y especialmente a Cataluña. ${ }^{29}$ La vía federal permitía obtener en este territorio autonomía y reconocimiento de su identidad

29 El representante y defensor más destacado del federalismo en España fue el político y estudioso catalán, Francesc Pi i Margall, presidente de la I República en España (18731874) y bajo la vigencia de la cual se elaboró el fracasado proyecto de Constitución federal de 1873 (Alejandro Nieto, 2016, pp. 1077-1078).

Esta obra está bajo una Licencia Creative Commons Atribución-NoComercial-SinDerivar 4.0 Internacional, IIJ-UNAM. Boletín Mexicano de Derecho Comparado, núm. 160, enero-abril de 2021, pp. 155-190. 
Esta revista forma parte del acervo de la Biblioteca Jurídica Virtual del Instituto de Investigaciones Jurídicas de la UNAM

regional dentro de España. Las ideas federales han sido importantes particularmente para el movimiento catalanista y también para el movimiento obrero y anarquista. ${ }^{30}$

La opción federal estuvo presente en la elaboración de la Constitución de 1978. No es una casualidad que la Constitución evite la palabra "federal". ${ }^{31}$ Si se hubiera introducido la palabra "federal" o "federalismo", no hubiera sido posible el consenso constitucional. Sin embargo, a pesar de las reticencias hacia el federalismo (todavía hoy), para la mayoría de la academia española el Estado autonómico funciona en la praxis como un sistema federal.

El federalismo ha despertado en España un gran interés en la doctrina, en particular, entre los iuspublicistas. Sin embargo, el federalismo no ha tenido el mismo eco en la mayoría de los partidos políticos. No está en el discurso del partido conservador, ni liberal, que no han mostrado ninguna empatía por el término "federal". Los partidos nacionalistas y separatistas no simpatizan con el federalismo porque significa igualdad y pacto, mientras que ellos reivindican un estatus especial o, en su caso, la independencia. El único partido que ha asumido el federalismo en su discurso es la socialdemocracia y, claramente, la socialdemocracia catalana. ${ }^{32}$ Pocos políticos y pocos ciudadanos saben qué es y qué significa ser un Estado federal.

En España, el término federalismo no es una palabra políticamente "neutra". La vinculación del federalismo con determinados partidos políticos - y, por tanto, con una ideología - es un problema porque lo convierte en la opción de un determinado partido y no se entiende como una forma de Estado que nada tiene que ver con la ideología de un partido. Por esa razón, el Estado autonómico difícilmente se definirá textualmente en una eventual reforma como federal. Ciertamente, el federalismo no se percibe en la actualidad abiertamente como factor de disgregación

30 Gumersindo Trujillo Fernández (1967, pp. 91-135). El catalanismo es un movimiento que reivindica los valores y la cultura catalanes. Su relevancia política se inició en la segunda mitad del siglo XIX, véase John H. Elliott (2018, p. 249).

31 Sobre ello, Xavier Arbós (2006, p. 35).

32 El PSC representa en Cataluña al PSOE. Las Declaraciones del PSOE sobre el federalismo: Declaración de Granada (2013) y Declaración de Barcelona (2017), http:// wrere.psoe.es.

Esta obra está bajo una Licencia Creative Commons

Atribución-NoComercial-SinDerivar 4.0 Internacional, IIJ-UNAM.

Boletin Mexicano de Derecho Comparado, núm. 160, enero-abril de 2021, pp. 155-190. 
Esta revista forma parte del acervo de la Biblioteca Jurídica Virtual del Instituto de Investigaciones Jurídicas de la UNAM

- como en el pasado - , pero la palabra federal en España todavía se evita y todavía genera en ciertos sectores un absoluto rechazo.

2. Objetivos y contenidos de una reforma federal:

great expectations, pero grandes discrepancias

\section{A. ¿Para qué el federalismo y qué modelos?}

No hay duda. La parte que precisa una reforma más urgente de la $\mathrm{CE}$ es la correspondiente a la organización territorial. Un alto porcentaje de la población en Cataluña apoya la independencia, pero simultáneamente se muestra en favor de una reforma de las comunidades autónomas que les conceda más autonomía. ${ }^{33}$

La reforma constitucional del Estado autonómico en sentido federal es la propuesta que cuenta con sólidos apoyos en la doctrina iuspublicista. ${ }^{34}$ La idea federal en España sólo puede entenderse en conexión con la existencia de nacionalismos y separatismos (Juan José Solozábal Echavarría, 2017a, pp. 15 y 16). El objetivo primordial sigue siendo el mismo a lo largo de nuestra historia: integrar a los movimientos nacionalistas y separatistas para salvaguardar la unidad mediante la autonomía y el reconocimiento de las identidades regionales.

Es extremadamente difícil lograr este objetivo: ¿es posible conseguirlo?, y, en ese caso, ¿cómo hacerlo? Es muy poco probable que los términos "federal" o "federalismo" aparezcan en una futura reforma constitucional. Pero, llegado el caso, tal reforma deberá plantearse elementos del federalismo. $^{35}$

$3371.9 \%$ en Cataluña (frente 45.4\% en el conjunto de España): CEO Dossier de premsa de l'enquesta "Percepció sobre el debat territorial a Espanya. 2019", 38, http://wrwre. ceo.gencat.cat.

34 Veáse, entre otros, una de las últimas propuestas elaborada por un grupo de profesores de Derecho constitucional y de Derecho administrativo: Ideas para la reforma de la Constitución (2017) http://wwre.idp.net. Anteriormente, remarcable el Informe del Consejo de Estado sobre las modificaciones de la Constitución Española (Francisco Rubio Llorente y José Álvarez Junco, 2006).

35 Ramón Punset Blanco y Leopoldo Tolivar Alas (2020; en particular, el trabajo de Juan José Solozábal Echavarría, p. 32). 
Esta revista forma parte del acervo de la Biblioteca Jurídica Virtual del Instituto de Investigaciones Jurídicas de la UNAM

El federalismo sirve para integrar la diversidad y puede ser una alternativa a la disgregación. La concesión de autonomía y la participación en el nivel federal son instrumentos que han acreditado su solvencia para reducir tensiones internas y restablecer la estabilidad del Estado y de la vida constitucional. ${ }^{36}$ En Europa, no hay ningún Estado federal que haya sido un Estado federal y haya dejado de serlo. Por el contrario, Estados tradicionalmente centralizados han asumido elementos de los Estados federales (Pedro Cruz Villalón, 2013, p. 59).

El derecho comparado puede desempeñar aquí un papel crucial. ${ }^{37}$ Hay una pluralidad de sistemas federales. El federalismo alemán es uno de los paradigmas más destacados en España, pero también Canadá y el Reino Unido son otros modelos para tener en cuenta, porque comparten con el Estado autonómico tendencias secesionistas. En todo caso, España deberá encontrar su propio modelo de organización territorial, que comprenda su peculiar contexto. La perspectiva comparada debe servir para conocer y discutir soluciones extranjeras. La recepción de soluciones de otros países debe hacerse con suma prudencia, pues muchas fórmulas pueden ser buenas y eficaces en su país de origen, pero quizá no funcionen en España (Wilhelm Hofmeister y José Tudela, 2017, p. 12).

\section{B. Vias de solución para problemas crónicos del Estado autonómico: reformas} jurídicas y no jurídicas

Debe quedar claro lo que una reforma constitucional puede conseguir y lo que no. Una reforma en sentido federal basada en un gran pacto constitucional puede no sólo servir para incrementar la autonomía en determinados territorios donde hay un sentimiento más fuerte de autogobierno, sino también para mejorar los problemas que viene arrastrando el Estado autonómico. Dicha reforma puede crear un marco normativo mejor que intente solucionar los problemas estructurales y funcionales y que los territorios, en los que hay demandas de secesión claras, vuelvan a sentirse parte de un todo o, por lo menos, aunque nunca dejen su senti-

36 Peter Hilpold (2008, p. 177); Alberto López Basaguren (2016, p. 55). Sobre Canadá después de los dos referéndums en Québec, Guy Laforest (2010, p. 11).

37 Sobre la relevancia creciente del método comparado en el espacio jurídico europeo, Armin von Bogdandy (2013, p. 177).

Esta obra está bajo una Licencia Creative Commons

Atribución-NoComercial-SinDerivar 4.0 Internacional, IIJ-UNAM.

Boletin Mexicano de Derecho Comparado, núm. 160, enero-abril de 2021, pp. 155-190. 
Esta revista forma parte del acervo de la Biblioteca Jurídica Virtual del Instituto de Investigaciones Jurídicas de la UNAM

miento independentista, puedan vivir dentro de un Estado en el que entienden que encuentran un acomodo.

Esta reforma constitucional en sentido federal del Estado autonómico debería mejorar aspectos que España comparte con los sistemas federales. Se debe conseguir una distribución más clara y eficiente de las competencias, un sistema de financiación más solidario y equitativo y unas relaciones entre el Estado central y las comunidades autónomas - en particular, la reforma del Senado-, que hagan más efectiva la integración de los distintos territorios en el Estado en su conjunto por medio de mecanismos de participación de las comunidades, tanto en asuntos domésticos, como en asuntos europeos.

Una reforma federal por sí sola no será suficiente, sin una lealtad institucional por parte del Estado central y de las comunidades autónomas, y sin lo que se da en llamar una cultura federal. En España, el principio de la lealtad constitucional, que se correspondería con el principio alemán de la Bundestreue, es también - como en el caso germano- un principio constitucional no escrito, pero en la jurisprudencia del Tribunal Constitucional español es más bien una especie de soft law que ni el Estado central, ni las comunidades autónomas han interiorizado (Pedro Cruz Villalón, 1990, p. 121)..$^{38}$

Resta el problema del thinking federal (Daniel J. Elazar, 1990, p. 33). En España, es necesaria otra perspectiva de la diversidad. Ello debe empezar por los políticos y por los funcionarios: ningún presidente del gobierno del Estado central ha hecho previamente carrera en la política autonómica y casi todos los funcionarios de Madrid proceden de Madrid y no de otras comunidades autónomas. Hay, por tanto, una marcada visión de los problemas "desde el centro" que queda reducida a ese círculo, donde se suele compartir una misma forma de ver y solucionar las cosas, muchas veces diversa de los puntos vista o de las sensibilidades "periféricos". Otro dato para reflexionar es que la gran mayoría de la población nunca ha vivido más de un año fuera de su comunidad autónoma. ${ }^{39}$ Es necesaria más movilidad para conocer y comprender la pluralidad.

38 En general, sobre la lealtad institucional en España, Leonardo Álvarez Álvarez (2008, pp. 493-524).

39 En Cataluña el 78.2\% y en el resto de España el 73.4\%. CEO Dossier de premsa de l'enquesta "Percepció sobre el debat territorial a Espanya. 2019", 51, http://wrere.ceo. gencat.cat. 
Esta revista forma parte del acervo de la Biblioteca Jurídica Virtual del Instituto de Investigaciones Jurídicas de la UNAM

Hay otro punto que debería contemplar la reformulación del Estado autonómico en clave federal: la reforma de la administración local. Hasta el momento, el foco de los desafíos de la organización territorial española se ha planteado en las relaciones entre el Estado y las comunidades autónomas, sin contemplar la administración local. Esa marginación de uno de los niveles de organización territorial se debe a que la administración local no ha sido considerada como un sujeto institucional relevante en el Estado autonómico (Manuel Zafra Víctor, 2012, pp. 82 y 83). El debate en este punto debe centrarse, principalmente, en cuál debe ser el futuro de la provincia y de sus órganos de gobierno, las diputaciones provinciales.

La provincia ha devenido un "cascarón vacío" (Santiago Muñoz Machado, 2007, p. 245), pero su supresión - como nivel de la administración territorial $-40 \mathrm{y}$ de las diputaciones provinciales es una cuestión compleja. Por un lado, se trata de un tema fuertemente emocional, ya que los sentimientos sobre la provincia varían ostensiblemente entre territorios. Por otro, es una cuestión de cirugía jurídica mayor, pues precisa una reforma constitucional y además debería enmarcarse en una reforma legal del régimen local de gran envergadura. ${ }^{41}$

\section{Vias de solución para las demandas de secesión: plurinacionalidad, asimetría y... ¿un derecho a la secesión?}

Sólo una reforma de estos aspectos no resolverá el problema de Cataluña. Cataluña y el País Vasco nos llevan de nuevo a un tema largamente conocido en nuestra historia y en el Estado autonómico: cuál y cómo debe ser el reconocimiento y la garantía de una identidad regional propia y diferenciada en determinados territorios. En relación con ello, se plantean

40 En ningún caso, se discute la supresión de la provincia como circunscripción electoral, esto es, como división del territorio para la elección de diputados y senadores, prevista como tal en la Constitución. En España, hay 50 provincias: Instituto Nacional de Estadística: http://wrere.ine.es. De acuerdo con los artículos 68.1 de la CE y artículos 69.2,3 y 4. de la CE: resultan 52 circunscripciones para el Congreso de los Diputados y 59 para el Senado.

41 Pedro Escribano Collado (2016, pp. 1995-2017); Miguel Sánchez Morón (2017, pp. 46-51). Un documento importante, aunque no propició una reforma constitucional, como el Informe del Consejo de Estado sobre Modificaciones de la Constitución española (E 1/2005), de febrero de 2006 propuso eliminar la provincia como entidad local (apartado IV.5.4, pp. 201-205).

Esta obra está bajo una Licencia Creative Commons

Atribución-NoComercial-SinDerivar 4.0 Internacional, IIJ-UNAM.

Boletín Mexicano de Derecho Comparado, núm. 160, enero-abril de 2021, pp. 155-190. 
Esta revista forma parte del acervo de la Biblioteca Jurídica Virtual del Instituto de Investigaciones Jurídicas de la UNAM

tres viejas cuestiones que han vuelto a aflorar: la plurinacionalidad del Estado, las asimetrías y un eventual derecho a la secesión.

La definición como Estado plurinacional no está expresamente en las Constituciones europeas. ${ }^{42}$ En la elaboración de la Constitución, Cataluña quiso identificarse como "nación", un término que no fue aceptado. ${ }^{43}$ En su lugar, se incluyó "nacionalidad" en el artículo 2 de la CE ("reconoce y garantiza el derecho a la autonomía de las nacionalidades y regiones"). La palabra "nacionalidad" (como "nación" o "plurinacionalidad") es extraña por lo menos en los federalismos centroeuropeos - referentes en el Estado autonómico - donde es más común referirse a identidades regionales al hablar de federalismo.

La propuesta de introducir en una reforma de la Constitución la fórmula de España como "Nación de Naciones" o como "Estado plurinacional" pretende dar un mayor reconocimiento a Cataluña y, al País Vasco, que no aceptará menos y, sobre todo apaciguar las reivindicaciones separatistas. Estas formulaciones se basan en la distinción entre dos conceptos de nación: la cultural y la política. La única nación política sería España, pero podrían existir también naciones culturales dentro de esa unidad. ${ }^{44}$

El concepto de plurinacionalidad abre, sin embargo, muchos interrogantes jurídicos: ¿cuántas naciones culturales hay? ¿quién decide qué territorio es una nación?, ¿con qué criterios? y ¿qué consecuencias se extraen de ello? Desde el punto de vista político, posiblemente, el reconocimiento de la plurinacionalidad es insuficiente para los separatistas que demandan el derecho a la autodeterminación, salvo que la plurinacionalidad pueda interpretarse como una puerta hacia el derecho a la secesión.

La cuestión de la asimetría tampoco es nueva ni en España, ni en el mundo del federalismo comparado (por ejemplo, significativamente

42 Por el contrario, la plurinacionalidad se menciona en las Constituciones latinoamericanas. La Constitución de Bolivia de 2009 prevé incluso el reconocimiento expreso como Estado plurinacional. En el ámbito europeo, por ejemplo, en Gran Bretaña, se acepta en su vocabulario la referencia a Escocia como nación (Michael Keating, 2015, p. 74).

43 Entrevista a Miquel Roca, uno los "padres" de la Constitución Española. La Vanguardia (06/12/2018), https://wwre.lavanguardia.com.

44 En la doctrina iuspublicista, en favor, Juan José Solozábal Echavarría (2017b, pp. 16 23); muy críticos, Roberto L. Blanco Valdés (2005, pp. 119-145); Francisco Sosa Wagner e Igor Sosa Mayor (2007, pp. 167-185). Entre los historiadores, José Álvarez Junco (2016, pp. 213-282). Una visión más allá de la percepción en España,Joseph Weiler (2018, pp. 7-18). 
Esta revista forma parte del acervo de la Biblioteca Jurídica Virtual del Instituto de Investigaciones Jurídicas de la UNAM

en Canadá o Italia). La CE diseña y permite la asimetría. ${ }^{45}$ La asimetría existe en la CE en virtud de los llamados "hechos diferenciales" de algunas comunidades autónomas. Se trata de circunstancias objetivas, como la historia o la lengua propia, con base en los cuales esas comunidades autónomas ostentan una posición peculiar respecto al resto.

La mayor asimetría que ampara la $\mathrm{CE}$ en el caso de algunas comunidades autónomas es la existencia de un sistema de financiación propio en el País Vasco y Navarra con base en derechos históricos, conocidos como "derechos forales". Una supresión de este privilegio o de los derechos forales en la Constitución es impensable. Extender el sistema vasco a otras comunidades autónomas, además de dudas jurídicas, plantea problemas sobre su viabilidad económica.

Cataluña, y otras comunidades autónomas, tienen competencias en materia de lengua que se proyectan también en sus competencias en cultura y educación. En este ámbito, hay un fuerte componente emocional en la defensa de la lengua catalana. En Cataluña, hay un modelo educativo donde la lengua vehicular es el catalán. Asimismo, Cataluña tiene también competencias en materia de derecho civil propio. Es la comunidad autónoma que más uso ha hecho de esas competencias hasta el punto de que Cataluña tiene un código civil propio (la Compilació de Dret civil de Catalunya).

Una vía de las vías que más se discuten para introducir nuevas asimetrías es introducir una nueva disposición adicional en la Constitución para Cataluña que reconozca sus derechos históricos: igual que existe una disposición adicional vasca y navarra, habría una disposición adicional catalana. Con base en esa previsión, Cataluña podría pedir un sistema de financiación como el vasco y podría blindar su sistema educativo en lengua catalana algo que forma parte de la idiosincrasia, del "núcleo duro", de la autonomía catalana.

Pero ¿y las otras comunidades autónomas?, ¿van a aceptar más asimetrías? Las asimetrías pueden provocar agravios comparativos inaceptables para el resto de las comunidades autónomas. Aunque la igualdad de los territorios acostumbra a ser un pilar de los sistemas federales, la perspectiva comparada muestra que hay países (por ejemplo, Canadá), donde existe un cierto margen para la asimetría. La CE permite la asimetría, pero

45 Luis López Guerra (1995, p. 178); Enric Fossas (1999, pp. 275-297).

Esta obra está bajo una Licencia Creative Commons

Atribución-NoComercial-SinDerivar 4.0 Internacional, IIJ-UNAM.

Boletin Mexicano de Derecho Comparado, núm. 160, enero-abril de 2021, pp. 155-190. 
Esta revista forma parte del acervo de la Biblioteca Jurídica Virtual del Instituto de Investigaciones Jurídicas de la UNAM

en casos muy limitados. La experiencia con el sistema de financiación vasco pone a las claras que las asimetrías son conflictivas y difícilmente asumibles por el resto de los territorios. ${ }^{46}$

El reconocimiento y la garantía de la plurinacionalidad y de la asimetría no son con toda seguridad propuestas fáciles, pero no se puede negar que hay cierto margen jurídico. Aunque la CE no prevé ni cláusulas de intangibilidad en el caso de su reforma, ni la democracia militante, parece realmente difícil un eventual reconocimiento y garantía en el texto constitucional del ius secessionis, una aspiración de nacionalistas y separatistas.

El Tribunal Constitucional ha negado con rotundidad que haya un derecho de secesión en la Constitución. Asimismo, el alto tribunal ha rechazado la existencia de un "derecho a decidir", un concepto usado por el movimiento separatista que el tribunal viene a equiparar con el derecho a la autodeterminación. El Tribunal Constitucional ha recordado también que durante la elaboración de la Constitución se descartó justamente la propuesta de reconocer el derecho a la autodeterminación de los pueblos del Estado. ${ }^{47}$ Asimismo, ha recurrido en su argumentación al derecho público comparado, donde tampoco se constatan precedentes de reconocimiento del ius secessionis en los sistemas federales y con un mayor nivel de descentralización territorial. ${ }^{48}$

\section{Las ideas federales y la política constitucional: la reforma constitucional como mission impossible $o$ ¿hay otras salidas?}

La reforma de la Constitución sería la opción óptima. Es la sede normativa donde deben estar las normas básicas de la división territorial

46 Sobre los problemas de las asimetrías véase Stephan Dion (1999, pp. 197-213).

47 STC 114/2017 y STS 459/2019, del 14 de octubre de 2019.

48 STC 114/2017, recuerda como "excepción anecdótica", Etiopía y el Archipiélago de San Cristóbal y Las Nieves. Asimismo, recuerda que existe acuerdo en que las Constituciones de Sudáfrica (sección 235 de su Constitución), Canadá (Reference Re Secession of Quebec del Tribunal Supremo, del 20 de agosto de 1998) o Estados Unidos (Texas vs. White, 1868, Tribunal Supremo) no amparan un derecho a la secesión. El Tribunal Constitucional recuerda también, que los Tratados internacionales prevén el derecho a la autodeterminación en contextos de descolonización. Sobre el derecho a decidir en España, en favor, en particular, Mercè Barceló Serramalera et al., 2015, en contra, entre otros, Joaquín Tornos (2019, pp. 19 y 20). Sobre la posibilidad de constitucionalizar el derecho a la sece- 
Esta revista forma parte del acervo de la Biblioteca Jurídica Virtual del Instituto de Investigaciones Jurídicas de la UNAM

del poder. Sin embargo, la reforma de la Constitución es una decisión política que necesita un pacto político y, en España, no existe una cultura política de búsqueda del consenso. La historia y más cuarenta años de vida constitucional en democracia constatan que la cultura de la reforma constitucional no está en nuestro ADN nacional. ${ }^{49}$

Hubo consenso en 1978 y, ulteriormente, sólo en momentos muy puntuales. A diferencia de muchos Estados europeos, en Madrid no ha habido nunca un gobierno de gran coalición. No existe tampoco una tradición de coaliciones (la primera coalición se produjo en diciembre de 2019 entre PSOE-Podemos). Hay una tendencia al conflicto y a la polarización. La política se basa en la lógica que divide entre amigo y enemigo. Quien pacta, cede y quien cede es traidor. Con esa forma de hacer política, es lógico que las reformas constitucionales sean poco habituales en España. ${ }^{50}$

Sería también un grave error acometer una reforma constitucional $\mathrm{u}$ otras relevantes reformas en un momento de enorme tensión o crispación. Un acuerdo de los dos grandes partidos sobre el Estado autonómico parece impensable, pues ambos partidos defienden opciones opuestas. Y, sin embargo, una reforma del Estado autonómico necesita el pacto de los dos grandes partidos en España. Una reforma constitucional que aborde la organización territorial debe involucrar también a los partidos nacionalistas y separatistas, pero sus reivindicaciones - en particular, su principal reivindicación, un referéndum de autodeterminación - resultan inasumibles por los dos grandes partidos.

La palabra diálogo es la más invocada para resolver la crisis, pero el diálogo requiere abrir el baile con temas concretos sobre los que se pueda empezar a hablar, discutir, negociar y, en su caso, llegar a acuerdos.

Imaginar que una reforma constitucional llegue a prever un derecho a la secesión, parece (por el momento) imposible. Por su parte, la convocatoria de un referéndum sobre la autodeterminación, pactada con el

sión en España,Benito Aláez Corral (2015, pp. 136-183). En general sobre el derecho a la autodeterminación, Peter Hilpold (2008, pp. 117-141).

49 Marta Lorente (2018, p. 2008); Ignacio Sotelo (2006, p. 70).

50 En cuarenta años de vida de la CE, sólo se han llevado a cabo dos reformas constitucionales. La primera, en 1992, sirvió para introducir el derecho sufragio activo de los ciudadanos de la Unión Europea en las elecciones locales (CE, art. 13.2), y, la segunda, en 2011, con relación al límite de endeudamiento público a raíz de la crisis económica y financiera (CE, art. 135). 
Esta revista forma parte del acervo de la Biblioteca Jurídica Virtual del Instituto de Investigaciones Jurídicas de la UNAM

Estado central, no es una opción jurídica viable de acuerdo con la actual jurisprudencia del Tribunal Constitucional que considera posible un referéndum de ese estilo, pero mediante una previa reforma de la Constitución, pues el propio texto constitucional garantiza la unidad y la indivisibilidad de España en los términos vistos. ${ }^{51}$ En el Tratado de la Unión Europea, estas cuestiones, así como si un Estado permite o no permite la secesión corresponde a "su identidad nacional" (TUE, art. 4.2). ${ }^{52}$

Ante ese escenario, resulta muy difícil romper el círculo vicioso y surge irremediablemente la siguiente cuestión: ¿hay otras salidas? Los aspectos que tienen un problema "de origen", esto es, que están deficientemente regulados en la propia la Constitución y esa es la causa directa de la disfunción, deben abordarse con una reforma constitucional, como el Senado. Sin embargo, existen otros muchos aspectos donde no es imprescindible la reforma constitucional.

Hay problemas del Estado autonómico que podrían cambiarse sin necesidad de reformas jurídicas. Para ello, bastaría con que se cambiaran dinámicas políticas: la mejoras en la cooperación vertical y horizontal pasan por cambios de comportamiento en los actores, fundamentalmente, los gobiernos, tales como hacer funcionar la Conferencia de Presidentes, impulsar un mayor papel de las comunidades autónomas en las conferencias sectoriales, o colaborar entre ellas mismas sin el gobierno central. Asimismo, hay temas que requieren reformas jurídicas sin que sea obligatoria una reforma constitucional: así, en materia de financiación, o en materia de transferencia de competencias del Estado central a las comunidades autónomas.

Con la prudencia que aconsejan los hechos - el escenario es dinámico y la política a veces imprevisible--, parece probable que la resolución de la crisis de Cataluña haya de conducir al reconocimiento de más asime-

51 Las referencias a la indivisibilidad en otras Constituciones europeas, véase Albert Weber (2019, p. 177).

52 Artículo 4.2 TUE: "La Unión respetará la igualdad de los Estados miembros ante los Tratados, así como su identidad nacional, inherente a las estructuras fundamentales políticas y constitucionales de éstos, también en lo referente a la autonomía local y regional. Respetará las funciones esenciales del Estado, especialmente las que tienen por objeto garantizar su integridad territorial, mantener el orden público y salvaguardar la seguridad nacional. En particular, la seguridad nacional seguirá siendo responsabilidad exclusiva de cada Estado miembro". 
Esta revista forma parte del acervo de la Biblioteca Jurídica Virtual del Instituto de Investigaciones Jurídicas de la UNAM

tría financiera y competencial. El Tribunal Constitucional en la sentencia sobre el Estatuto de Autonomía catalán de 2006 no declaró que muchas pretensiones fueran materialmente inconstitucionales, sino que se trataba de cuestiones que sólo podía regular el Estado central - como en el caso del sistema de financiación- y no el Estatuto de Autonomía de una comunidad autónoma, que es una norma pactada entre el Estado central y la correspondiente Comunidad. ${ }^{53}$

La cuestión de la financiación ha sido uno de los motivos que ha generado más apoyo de la población de Cataluña a la independencia. La CE no regula, como se indicó, este tema, sino que lo hace una ley del Estado central (CE, art. 157), la llamada Ley Orgánica para la Financiación de las Comunidades Autónomas. Por tanto, hay margen para introducir reformas legales en el sistema de financiación sin pasar necesariamente por una operación de revisión constitucional.

Asimismo, la Constitución dispone de instrumentos para crear asimetrías de competencias mediante un tipo especial de leyes del Estado central por medio de las cuales se pueden transferir o delegar en las comunidades autónomas "facultades correspondientes a materias de titularidad estatal que por su propia naturaleza sean susceptibles de transferencia o delegación" (CE, art. 150.2). Ambos casos serían leyes orgánicas: un tipo especial de ley que no necesita la mayoría de una reforma constitucional, pero sí precisa una mayoría reforzada (la mayoría absoluta del Congreso de los Diputados). En términos políticos, estas leyes requieren normalmente el pacto entre varios partidos que asegure dicha mayoría.

Existe, pues, un margen muy estrecho para reconocer materialmente nuevas asimetrías más allá de los hechos diferenciales previstos en la Constitución y cauces procedimentales para hacerlo. Su eventual reconocimiento se hará posiblemente con ambigüedad — la que muchas veces exige un complejo pacto político- y ello será más que probablemente fuente de conflictos de nuevo.

La utilización de fórmulas ambiguas no solucionará el problema y trasladará al Tribunal Constitucional la interpretación de temas con un contenido altamente político. Además, sería naif pensar que el resto de las comunidades autónomas van a aceptar privilegios para otras sin más y que los partidos separatistas renunciarán a más peticiones porque en su "pro-

53 STC 31/2010.

Esta obra está bajo una Licencia Creative Commons

Atribución-NoComercial-SinDerivar 4.0 Internacional, IIJ-UNAM.

Boletín Mexicano de Derecho Comparado, núm. 160, enero-abril de 2021, pp. 155-190. 
Esta revista forma parte del acervo de la Biblioteca Jurídica Virtual del Instituto de Investigaciones Jurídicas de la UNAM

grama de máximos" la meta final es la autodeterminación. Es necesario aceptar que las soluciones a las crisis sólo podrán ser con un alto grado de probabilidad provisionales. La historia se repite...

\section{CONCLUSión: El FUtuTO Del Estado AUTONÓMICO ES UNA INCÓGNITA}

La España actual no es posible como proyecto común sin un amplio reconocimiento de la autonomía territorial. El Estado autonómico se creó para dar respuesta a las fuertes demandas de autogobierno del País Vasco y Cataluña. El desarrollo del Estado autonómico en clave de simetría entre las comunidades autónomas, salvo algunas excepciones, no ha funcionado.

Una reforma de la Constitución, que reconozca a Cataluña una posición especial dentro de España, puede ser una opción en teoría. En la práctica, el problema radica en cómo negociar y concretar cuál debería ser esa posición especial para Cataluña (¿financiera?, ¿competencial?, ¿ambas?), la posición del resto y, en particular, del País Vasco, una comunidad autónoma ya con un estatus especial y con demandas secesionistas arraigadas, aunque (en estos tiempos) mucho menos activas que en Cataluña (Alberto López, 2020). Pero es muy difícil que el derecho a la autodeterminación se reconozca y se garantice en la Constitución.

La urgencia de las reformas en el Estado autonómico ha venido marcada por la crisis catalana. Hay que reflexionar por qué en Cataluña hay más de dos millones de personas que en los últimos diez años no quieren ser españoles y se jactan de desobedecer la Constitución. Cataluña, es el territorio en España donde la Constitución tiene menor apoyo social y ello no tiene visos de cambiar radicalmente a corto y a medio plazo. ${ }^{54}$

La vinculación que une a los ciudadanos con la Constitución debería restablecerse. Una Constitución sólo funciona si las personas creen en él y lo respetan. En caso contrario, la convivencia se desintegra y el sistema se puede acabar derrumbando (Rudolf Smend, 2010, pp. 136-142). En España, hace falta más pedagogía sobre la pluralidad y más formación acerca de los valores constitucionales sobre los que se ha producido el pe-

54 En 1978, más de 90\% de la población en Cataluña votó en favor de la CE. Hoy el porcentaje supera ligeramente $50 \%$. 
Esta revista forma parte del acervo de la Biblioteca Jurídica Virtual del Instituto de Investigaciones Jurídicas de la UNAM

riodo más largo de convivencia pacífica en España, unos valores que son también valores de la Unión Europea de la que formamos parte.

En España se vive con el separatismo. Esto no es nuevo. Siempre ha existido (José Ortega y Gasset, 1999, pp. 24 y 25). El ordenamiento constitucional permite ciertamente esta ideología, pero no la secesión unilateral. Corresponde al Estado proponer a la población, donde se incluye aquella que un día optó por un switch off emocional con España, un proyecto común atractivo. Los separatistas han conseguido crear una vinculación emocional muy fuerte hacia secesión, pero es necesario más realismo: la independencia no es fácil, las consecuencias económicas son graves y no hay mayoría para ello (con la cautela, de momento).

Sería deseable que los actores políticos para la reforma del Estado autonómico supieran recuperar el consenso que fue clave en 1978 para la aprobación de la Constitución de la democracia. El futuro del Estado autonómico es más incógnita que nunca. Sin embargo, hay que encontrar una salida. De lo contario, hay algo seguro: sin cambios políticos y jurídicos los problemas del Estado autonómico no tardarán en agudizarse.

\section{BIBLIOGRAFÍA}

AJA, Eliseo (2014). Estado autonómico y reforma federal. Alianza. AJA, Eliseo et al. (1985). Sistema jurídico de las comunidades autónomas. Tecnos. AlÁEz Corral, Benito (2015). Constitucionalizar la secesión para armonizar la legalidad constitucional y el principio democrático en Estados territorialmente descentralizados como España. Revista d'Estudis Federals i Autonòmics (22), 136-183.

Álvarez Álvarez, Leonardo (2008). La función de la lealtad en el Estado autonómico. Teoría y Realidad Constitucional (22), 493-524.

Álvarez Junco, José (2016). Dioses útiles. Naciones y nacionalismos. Galaxia Gutenberg.

ARAGÓn ReYes, Manuel (2006). La construcción del Estado autonómico. Revista General de Derecho Constitucional (1), 1-24.

ARBÓs MARÍn, Xavier (2006). Doctrinas constitucionales y federalismo en Espa$\tilde{n} a$. ICPS.

Barceló I Serramalera, Mercè et al. (2015). El derecho a decidir. Teoría y práctica de un nuevo derecho. Atelier.

Esta obra está bajo una Licencia Creative Commons

Atribución-NoComercial-SinDerivar 4.0 Internacional, IIJ-UNAM.

Boletín Mexicano de Derecho Comparado, núm. 160, enero-abril de 2021, pp. 155-190. 
Esta revista forma parte del acervo de la Biblioteca Jurídica Virtual del Instituto de Investigaciones Jurídicas de la UNAM

BAyOna, Antoni (2019). No todo vale. La mirada de un jurista a las entrañas del procés, (2a ed.). Península.

BLANCO VALDÉS, Roberto L. (2005). Nacionalidades históricas y regiones sin historia. Alianza.

CALAFEll FerRÁ, Vicente Juan (2006). Los convenios entre comunidades autónomas. CEPG.

Carmona Contreras, Ana M. (2019). Sobre el futuro de la Constitución: proyección y encaje europeos. Revista de las Cortes Generales (107), 61-92.

Cosculluela Montaner, Luis (2011). El debate sobre la abolición de la provincia y la reforma de las diputaciones. Anuario del Gobierno Local (pp. 45-67). Fundación Democracia y Gobierno Local.

CRUZ Villalón, Pedro (1981). La estructura del Estado o la curiosidad del jurista persa. Revista de la Facultad de Derecho de la Universidad Complutense (4), 53-63.

Gruz Villalón, Pedro (1990). La doctrina constitucional sobre el principio de cooperación. En Juan Cano Bueso (coord.), Comunidades autónomas e instrumentos de cooperación interterritorial (pp. 119-134). Madrid, Sevilla: Tecnos.

CruZ Villalón, Pedro (1991). La construcción jurisprudencial del Estado de las Autonomías. Revista Vasca de Administración Pública (31), 249260.

CRuZ Villalón, Pedro (2013). Rasgos básicos del derecho constitucional de los Estados en perspectiva comparada. En Armin VON BOGDANDY Pedro Cruz Villalón y Peter Huber, El derecho constitucional en el espacio jurídico europeo (pp. 15-68). Valencia: Tirant lo Blanch.

Dion, Stephan (1999). El federalismo fuertemente asimétrico: improbable e indeseable. En Enric Fossas y Ferran ReQueJO (eds.), Asimetría y Estado plurinacional. El debate sobre la acomodación de la diversidad en Canadá, Bélgica y España (pp. 197-215). Madrid: Trotta.

ELAZAR, Daniel J. (1990). Exploración del federalismo. Hacer.

Elliott, John H. (2018). Catalanes y escoceses. Taurus.

Escribano Collado, Pedro (2016). Provincias y diputaciones: una polémica sin proyecto institucional. En José María Baño León (coord.), Memorial para la reforma del Estado. Estudios en homenaje al profesor Santiago Muñoz Machado (pp. 1995-2017). Madrid: CEPG. 
Esta revista forma parte del acervo de la Biblioteca Jurídica Virtual del Instituto de Investigaciones Jurídicas de la UNAM

FOSSAS, Enric (1999). Asimetría y plurinacionalidad en el Estado autonómico. En Enric Fossas y Ferran Requejo (eds.), Asimetría y Estado plurinacional. El debate sobre la acomodación de la diversidad en Canadá, Bélgica y España (pp. 275-301). Madrid: Trotta.

FrowEIN, Jochen Abr. (1974). Die Rechtsprechung des Bundesverfassungsgerichts zum Wahlrecht. Archiv des öffentlichen Rechts, 99(1), 72-110. FroweIn, Jochen Abr. y Peukert. Wolfgang (2009). Europäische Menschenrechtskonvention EMRK-Kommentar (3a ed.). Kehl am Rhein, Straßburg, Arlington: N.P. Engel.

GARCÍA DE ENTERRÍA, Eduardo (1991). La provincia en la Constitución. En Rafael GómEZ-FERRER MORANT (dir.), La provincia en el sistema constitucional (pp. 5-17). Madrid: Diputación de Barcelona. Civitas.

García MORALES, María Jesús (2013). Intergovernmental Relations in Spain and the Constitutional Court Ruling on the Statute of Autonomy of Catalonia: What's Next? En Alberto LóPEZ BaSAGUREN y Leire Escajedo SAn EPIFANIO (eds.), The Ways of Federalism in Western Countries and the Horizons of Territorial Autonomy in Spain, II (pp. 83-109). Berlín: Heidelberg. Springer.

García Morales, María Jesús (2016). El gobierno central y los gobiernos autonómicos en España... ¿trabajan juntos? Istituzioni del federalismo (1), 117-161.

García Morales, María Jesús (2019). Bundeszwang und Sezession in Spanien: Der Fall Katalonien”. Die Öffentliche Verwaltung (1), 1-13.

GARCía ROGA, Javier (2019). Il tempo moderato de la intervención coercitiva del Estado (artículo155 de la CE) en Cataluña: un comentario a las SSTC 89 y 90/2019, en particular, proporcionalidad y test de necesidad o razonabilidad de las medidas. Teoría y Realidad Constitucional (44), 503-524.

GARRIDO LÓPEZ, Carlos y Eva SAÉNZ RoyO (2019). El referéndum autonómico y la peculiaridad española. En Carlos GARRIDO LÓPEZ y Eva SAÉNZ RoYo (coords.), Referéndums y consultas populares en el Estado autonómico (pp. 15-26). Madrid: Marcial Pons.

GÓMEZ-FERRER MORANT, Rafael (dir.) (1991). La provincia en el sistema constitucional. Diputación de Barcelona. Civitas.

GonzÁlez GARCíA, Ignacio (2011). Parlamento y convenios de cooperación. CEPG. 
Esta revista forma parte del acervo de la Biblioteca Jurídica Virtual del Instituto de Investigaciones Jurídicas de la UNAM

HilPOLD, Peter (2008). Die Sezession - zum Versuch der Verrechtlichung eines faktischen Phänomens. Zeitschrift für öffentliches Recht (63), 117-141.

Hofmeister, Wilhelm y Tudela, José (2017). "Prefacio". En Wilhelm Hofmeister y José Tudela (eds.), Sistemas federales. Una comparación internacional (pp- 7-12). Konrad Adenauer Stiftung, Fundación Manuel Giménez Abad.

INE (2019). España en cifras 2019. Madrid. Catálogo de Publicaciones de la Administración General del Estado. http://ine.es

KeAting, Michael (2015). The Scottish Independence Referendum and After. Revista d'Estudis Federals i Autonòmics (21), 73-98.

Kuhlmann, Sabine y Wollmann, Hellmut (2019). Introduction to Comparative Public Administration (2a ed.). Cheltenham y Northampton. Edward Elgar Publishing.

SOlÉ TURA, Jordi (2019). Nacionalidades y nacionalismos. El Viejo Topo.

LAFOREST, Guy (2010). The meaning of Canadian Federalism in Quebec. Revista d'Estudis Federals i Autonòmics (11), 10-55.

López Basaguren, Alberto (2016). Crisis del sistema autonómico y demandas de secesión: ¿es el sistema federal "la alternativa"? Teoría y Derecho (19), 46-61.

López Basaguren, Alberto (2020). El País Basc i la reforma territorial. Politica \& Prosa (17). https://politicaprosa.com/el-pais-basc-i-la-reforma-territorial/

LÓPez Guerra, Luis (1995). El modelo autonómico. Autonomies. Revista Catalana de Dret Públic (20), 171-186.

Lorente Sariñena, Marta (2018). De la reforma de la Constitución. Breve historia de una ausencia (1810-1978). En Benigno PENDÁs (dir.), España constitucional (1978-2018). Trayectorias y Perspectivas, I (pp. 43774389). Madrid: CEPC.

Miguel BÁRCEnA, Josu de (2018). El proceso soberanista ante el Tribunal Constitucional. Revista Española de Derecho Constitucional (113), 133-166.

Muñoz Machado, Santiago (2007). Derecho público de las comunidades autónomas, II. (2a ed.). Iustel.

MuÑoz Machado, Santiago (2013). Crisis y reconstitución de la estructura territorial del Estado. Iustel.

Nieto García, Alejandro (2016). El federalismo español en 1873. En José María BAÑo LEÓN (coord.), Memorial para la reforma del Estado. Estu- 
Esta revista forma parte del acervo de la Biblioteca Jurídica Virtual del Instituto de Investigaciones Jurídicas de la UNAM

dios en Homenaje al profesor Santiago Muñoz Machado (pp. 1069-1088). Madrid: CEPG.

Nohlen, Dieter y SchulTze, Rainer-Olaf (1985). Los efectos del sistema electoral español sobre la relación entre sufragios y escaños. Un estudio con motivo de las elecciones a Cortes de 1982. Revista Española de Investigaciones Sociológicas (30), 179-200.

NoHLen, Dieter (2019). La democracia. Instituciones, Contexto y Conceptos. Ediciones Olejnik.

OrTega y Gasset, José (1967). La redención de las provincias. Alianza Editorial.

ORTEGA Y GASSET, José (1999). España invertebrada. Universidad de Extremadura. Servicio de Publicaciones.

PALLARÉS, Francesc (2018). Las elecciones catalanas del 21-D-2017. Informe Comunidades Autónomas 2017 (pp. 425-443). IDP.

PlazA, Carmen (2018). Catalonia's secession process at the Constitutional Court: A Never-Ending Story? European Public Law, 24(3), 373-392.

Porras Ramírez, José María (2021). Der spanische Senat als Kammer der territorialen Vertretung. Eine anstehende Verfassungsreform. En Hermann-Josef Blanke; Siegfried Magiera; Christian Pielow y Albrecht WEBER (eds.), Verfasssungsentwicklungen im Vergleich: Italien 1947 Deutschland 1949 - Spanien 1978 (pp. 332-334). Duncker \& Humblot.

Punset Blanco, Ramón y TOlivar Alas, Leopoldo (coord.) (2020). España: el federalismo necesario. Reus.

QUINTERO OlivareS, Gonzalo (2019a). La "sentencia catalana" y la desobediencia. Teoría y Derecho (26), 68-73.

QUiNTERO OLIVARES, Gonzalo (2019b). La tormenta catalana y la capacidad del derecho penal: sobre la Sentencia 459/2019, del 14 de octubre de 2019. El Cronista del Estado Social y Democrático de Derecho (82-83), 68-73.

Roig Molés, Eduard (2017). Procés sobiranista i Tribunal Constitucional. Anàlisi d'un impacte recíproc. Revista catalana de dret públic (54), 2461.

Rubio Llorente, Francisco y Álvarez Junco, José (eds.) (2006). Informe del Consejo de Estado sobre la reforma constitucional. Texto del informe y debates académicos. Consejo de Estado y CEPG.

Esta obra está bajo una Licencia Creative Commons

Atribución-NoComercial-SinDerivar 4.0 Internacional, IIJ-UNAM.

Boletín Mexicano de Derecho Comparado, núm. 160, enero-abril de 2021, pp. 155-190. 
Esta revista forma parte del acervo de la Biblioteca Jurídica Virtual del Instituto de Investigaciones Jurídicas de la UNAM

SAlvAdOR CRESPO, Mayte (2007). La autonomia provincial en el sistema constitucional español. Intermunicipalidad y Estado autonómico. Fundación Democracia y Gobierno Local, Instituto Nacional de Administración Pública. SÁnchez Morón, Miguel (2017). ¿Deben suprimirse las diputaciones provinciales? El Cronista del Estado Social y Democrático de Derecho (65), 4651.

SmEND, Rudolf (2010). Verfassung und Verfassungsrecht. En Rudolf Smend, Staatrechtliche Abhandlungen und andere Aufsätze (4a ed.) (pp. 117 276). Duncker \& Humblot.

Solozábal Echavarría, Juan José (2017a). Pensamiento político federal español: Azaloa, Solé Tura y Trujillo, Revista de Estudios Políticos, 178, $13-45$.

SolozÁbal EchaVARRía, Juan José (2017b.). España: Nación de Naciones. El Cronista del Estado Social y Democrático de Derecho (68), 237-252.

SOlOzÁBAl EchaVARRÍA, Juan José (2020). ¿Crear una federación o federalizar el Estado autonómico? En Ramón Punset Blanco y Leopoldo Tolivar Alas (coords.), España: el federalismo necesario (pp. 15-32) Madrid: Reus.

Sommermann, Karl-Peter (2015). "Citizen Participation in Multi-Level Democracies: An Introduction". En Christina Fraenkel-Haeberle; Sabine Kropp; Francesco Palermo y Karl-Peter Sommermann (eds.), Citizen Participation in Multi-Level Democracies (pp. 1-12). Leiden, Boston: Brill Nijhoff.

Sotelo Martínez, Ignacio (2006). España: un federalismo tan necesario como improbable. Política Exterior, 20 (111), 65-74.

Sosa Wagner, Francisco y Sosa MaYor, Igor (2007). El Estado fragmentado (4a ed.). Fundación Alfonso Martín Escudero. Trotta.

VON Bogdandy, Armin (2013). Historia y futuro del derecho Constitucional en Europa. En Armin VOn Bogdandy, Pedro GruZ Villalón y Peter Huber, El derecho constitucional en el espacio jurídico europeo (pp. 143180). Valencia: Tirant lo Blanch.

Tomás Mallén, Beatriz (2018). Art. 141. En Pablo Pérez Tremps y Alejandro SAIZ ARnAIZ (dirs.), Comentario a la Constitución Española. Librohomenaje a Luis López Guerra (pp. 1949-1961). Valencia: Tirant lo Blanch.

TORnOS MAS, Joaquín (2019). La inexistencia del derecho a decidir y la inexistencia de una causa de exoneración de responsabilidad penal. El Cronista del Estado Social y Democrático de Derecho (82-83), 18-23. 
Esta revista forma parte del acervo de la Biblioteca Jurídica Virtual del Instituto de Investigaciones Jurídicas de la UNAM

Tudela ARAnda, José (2016). El fracasado éxito del Estado autonómico. Marcial Pons.

TRUjILlO FERNÁNDEZ, Gumersindo (1967). Introducción al federalismo español (2a ed.). Cuadernos para el Diálogo.

WeBer, Albrecht (2019). European Constitutions Compared. Beck, Nomos, Hart.

ZABALZA, Antoni y LÓPEZ-LABORDA, Julio (2017). The uneasy coexistence of the Spanish foral and common regional finance systems. Investigaciones Regionales - Journal of Regional Research (37), 119-152.

VARELA SUANZES-CARPEGNA, Joaquín (2016). La cuestión territorial en las dos Repúblicas. En José María BAÑo LEÓn (coord.), Memorial para la reforma del Estado. Estudios en Homenaje al profesor Santiago Muñoz Machado (pp. 1089-1 109). CEPC.

Velasco Caballero, Francisco (2011). Provincias. En Manuel Aragón Reyes (dir.) y César AguAdo Renedo (coods.). Temas básicos de derecho constitucional. Tomo II (pp. 627-631). Aranzadi Thomson Reuters.

WEILER, Joseph H. H. (2018). ¿Quién teme a una nación de naciones? / Who's Afraid of a Nation of Nations?, Actualidad Furídica Uría Menéndez (50), 7-18.

ZAFRA, Víctor Manuel (2012). La provincial: lo importante no es el nombre, lo importante es la función. Intermunicipalidad en el Estado autonómico. El Cronista del Estado Social y Democrático de Derecho (27), 66-83. 